\title{
Oxygen exchange and ice melt measured at the ice-water interface by eddy correlation
}

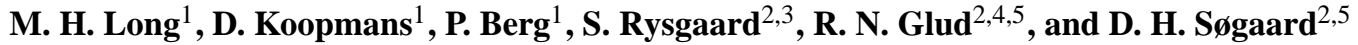 \\ ${ }^{1}$ Department of Environmental Sciences, University of Virginia, Charlottesville, Virginia, USA \\ ${ }^{2}$ Greenland Climate Research Centre, Greenland Institute of Natural Resources, Nuuk, Greenland \\ ${ }^{3}$ Centre for Earth Observation Science, CHR Faculty of Environment Earth and Resources, University of Manitoba, \\ Winnipeg, Canada \\ ${ }^{4}$ Scottish Association of Marine Sciences, Oban, Scotland, UK \\ ${ }^{5}$ Southern Danish University and NordCee, Odense M, Denmark
}

Correspondence to: P. Berg (pb8n@virginia.edu)

Received: 28 October 2011 - Published in Biogeosciences Discuss.: 23 November 2011

Revised: 13 April 2012 - Accepted: 24 April 2012 - Published: 4 June 2012

\begin{abstract}
This study examined fluxes across the ice-water interface utilizing the eddy correlation technique. Temperature eddy correlation systems were used to determine rates of ice melting and freezing, and $\mathrm{O}_{2}$ eddy correlation systems were used to examine $\mathrm{O}_{2}$ exchange rates driven by biological and physical processes. The study was conducted below $0.7 \mathrm{~m}$ thick sea-ice in mid-March 2010 in a southwest Greenland fjord and revealed low rates of ice melt at a maximum of $0.80 \mathrm{~mm} \mathrm{~d}^{-1}$. The $\mathrm{O}_{2}$ flux associated with release of $\mathrm{O}_{2}$ depleted melt water was less than $13 \%$ of the average daily $\mathrm{O}_{2}$ respiration rate. Ice melt and insufficient vertical turbulent mixing due to low current velocities caused periodic stratification immediately below the ice. This prevented the determination of fluxes $61 \%$ of the deployment time. These time intervals were identified by examining the velocity and the linearity and stability of the cumulative flux. The examination of unstratified conditions through vertical velocity and $\mathrm{O}_{2}$ spectra and their cospectra revealed characteristic fingerprints of well-developed turbulence. From the measured $\mathrm{O}_{2}$ fluxes a photosynthesis/irradiance curve was established by least-squares fitting. This relation showed that light limitation of net photosynthesis began at $4.2 \mu \mathrm{mol}$ photons $\mathrm{m}^{-2} \mathrm{~s}^{-1}$, and that algal communities were well-adapted to low-light conditions as they were light saturated for $75 \%$ of the day during this early spring period. However, the sea-ice associated microbial and algal community was net heterotrophic with a daily gross primary production of $0.69 \mathrm{mmol} \mathrm{O}_{2} \mathrm{~m}^{-2} \mathrm{~d}^{-1}$ and a respiration
\end{abstract}

rate of $-2.13 \mathrm{mmol} \mathrm{O}_{2} \mathrm{~m}^{-2} \mathrm{~d}^{-1}$ leading to a net ecosystem metabolism of $-1.45 \mathrm{mmol} \mathrm{O}_{2} \mathrm{~m}^{-2} \mathrm{~d}^{-1}$. This application of the eddy correlation technique produced high temporal resolution $\mathrm{O}_{2}$ fluxes and ice melt rates that were measured without disturbing the in situ environmental conditions while integrating over an area of approximately $50 \mathrm{~m}^{2}$ which incorporated the highly variable activity and spatial distributions of sea-ice communities.

\section{Introduction}

Sea-ice associated microbial communities can be an important component of marine polar food webs (Arrigo 2003) and when sea-ice is present it can host $30-65 \%$ of the ecosystem primary production (e.g. Mikkelsen et al., 2008; McMinn et al., 2010). Primary production and phototrophic growth in sea-ice is largely limited by the amount of light that transmits through the ice and snow cover (Arrigo, 2003; McMinn et al., 2010). Therefore production is tightly linked to photosynthetic efficiency, with sea-ice algae being welladapted to low light conditions (Mock and Gradinger, 1999; Kuhl et al., 2001; Rysgaard et al., 2008). Oxygen $\left(\mathrm{O}_{2}\right)$ fluxes are commonly used to determine photosynthetic production and respiration in aquatic ecosystems, however at the ice-water interface such measurements are complicated by an additional $\mathrm{O}_{2}$ flux contribution driven by the physical processes of melting and freezing (Glud et al., 2002). 
Specifically, sea-ice formation can cause a release of $\mathrm{O}_{2}$ supersaturated brines, while sea-ice melt can generate a release of $\mathrm{O}_{2}$ undersaturated melt water (Glud et al., 2002; Rysgaard et al., 2008), confounding measurements of primary production and respiration during periods of rapid freeze or melt. Therefore, to estimate the biotic $\mathrm{O}_{2}$ flux it is necessary to quantify the physical contribution from freezing and melting.

Sampling at the ice-water interface presents a number of challenges for traditional techniques for quantifying primary production and respiration. The techniques presently used to study sea-ice primary production sample at either one point on the ice surface or within an ice core, though algal patchiness and activity have been reported to vary across a much wider range (Gosselin et al., 1986; Rysgaard et al., 2001). This may lead to misrepresentation of the actual sea-ice environment and requires that many replicates are taken over a large area. A further limitation of conventional methods is their poor resolution of temporal variation, which has limited the studies of short-term variations in production and respiration in sea-ice microbial communities. The ${ }^{14} \mathrm{C}$ tracer method and ${ }^{3} \mathrm{H}$ labeled thymidine approach are the most widely applied techniques to determine primary production and bacterial production in sea-ice, respectively. However, both methods are time consuming, making multiple samples and a wide spatial coverage difficult (McMinn and Ashworth, 1998; Søgaard et al., 2010). Both approaches also require melting the ice to evenly distribute the tracers, which grossly changes the natural conditions experienced by the microalgae and bacteria (e.g. nutrient levels, light, and $\mathrm{O}_{2}$ gradients) (Glud et al., 2002; Rysgaard et al., 2008).

Pulse amplitude modulated (PAM) fluorometry represents a promising alternative to study the primary production of natural communities. However, when PAM is applied to intact ice cores the depth integrated signal is poorly defined and depends on variations in algae biomass as well as the optical properties of the ice (Rysgaard et al., 2001; Glud et al., 2002). The conversion of PAM data into carbon (or $\mathrm{O}_{2}$ ) fluxes further complicates the method as frequent intercalibration to poorly constrained empirical relationships are required. Microsensor profiling using both Clark-type $\mathrm{O}_{2}$ microsensors and $\mathrm{O}_{2}$ micro-optodes has also been used to examine icewater $\mathrm{O}_{2}$ fluxes but can suffer from calibration problems due to temperature and salinity gradients and spatial microvariability in the ice (McMinn and Ashworth, 1998; Glud et al., 2002; Mock et al., 2003; McMinn et al., 2007).

Eddy correlation in aquatic environments is a technique typically used for measuring fluxes across the sedimentwater interface by correlating high temporal resolution measurements of velocity and a scalar quantity of interest (Berg et al., 2003). Oxygen eddy correlation systems have been used to determine photosynthesis and respiration in muddy marine benthic systems and river bottoms (Berg et al., 2003), sandy sediments (Kuwae et al., 2006; Berg and Huettel, 2008; Reimers et al., 2012), the deep ocean (Berg et al., 2009), lakes (Brand et al., 2008; McGinnis et al., 2008;
Lorrai et al., 2010), hard-bottom arctic substrates (Glud et al., 2010), and seagrass beds (Hume et al., 2011). With the eddy correlation technique measurements are conducted under true in situ conditions, i.e. without disturbing the surface and under natural light and hydrodynamic conditions (Berg et al., 2003). The technique also integrates over a large surface area, typically tens of meters long and a few meters wide (Berg et al., 2007). For these reasons, the technique is ideal for applications under sea-ice allowing fluxes across the icewater interface to be examined non-invasively. The eddy correlation technique has been used to determine fluxes of momentum, heat, and salt beneath sea-ice (McPhee, 1992; Shirasawa et al., 1997; Widell et al., 2006; McPhee et al., 2008) but has not previously been used to quantify $\mathrm{O}_{2}$ exchange and thereby production and respiration of sea-ice microbial communities. In this study we present results obtained with $\mathrm{O}_{2}$ eddy correlation systems and temperature eddy correlation systems that are used collectively to determine true in situ $\mathrm{O}_{2}$ exchange rates and thereby non-invasively determine the primary production and respiration of sea-ice algal communities.

\section{Methods}

\subsection{Site description}

Measurements were performed in a small tributary fjord near Kapisigdlit, Greenland from 12-17 March, 2010. The subArctic fjord is located in southwest Greenland and is part of the Nuup Kangerlua Fjord. The fjord was partially covered with ice at a thickness of $\sim 70 \mathrm{~cm}$ and a snow cover of $\sim 2 \mathrm{~cm}$ during the sampling period. Measurements were conducted beneath the ice, $100 \mathrm{~m}$ from open water. Air temperatures during the study period ranged from $-8.8^{\circ} \mathrm{C}$ to $+2.9^{\circ} \mathrm{C}$ with an average temperature of $-3.2^{\circ} \mathrm{C}$. Water depth at the deployment location varied between 40 and $45 \mathrm{~m}$. The concentration of chlorophyll $a$ in the bottom $12 \mathrm{~cm}$ of ice was $2.8 \pm 0.4 \mu \mathrm{g} \mathrm{L}^{-1}(\mathrm{SE}, n=3)$ and the average concentration across the entire ice thickness was $1.0 \pm 1.2 \mu \mathrm{g} \mathrm{L}^{-1}$ (SE, $n=3)$.

\subsection{Eddy correlation measurements}

Two $\mathrm{O}_{2}$ eddy correlation systems and two temperature eddy correlation systems were deployed beneath the ice. The $\mathrm{O}_{2}$ eddy correlation system consists of an acoustic Doppler Velocimeter (ADV) (Nortek AS, Norway) that has been modified to record measurements made with a high-resolution custom-made pA amplifier (Max Planck Institute for Marine Microbiology, Germany) to which a fast responding $(<0.2 \mathrm{~s})$ Clark-type $\mathrm{O}_{2}$ microsensor is mounted (Berg and Huettel, 2008, Berg et al., 2009; Hume et al., 2011). The temperature eddy correlation system consists of a standard ADV coupled to a rapid-response $(<0.1 \mathrm{~s})$ temperature and conductivity sensor (Fast CT sensor, Precision Measurement Engineering, 


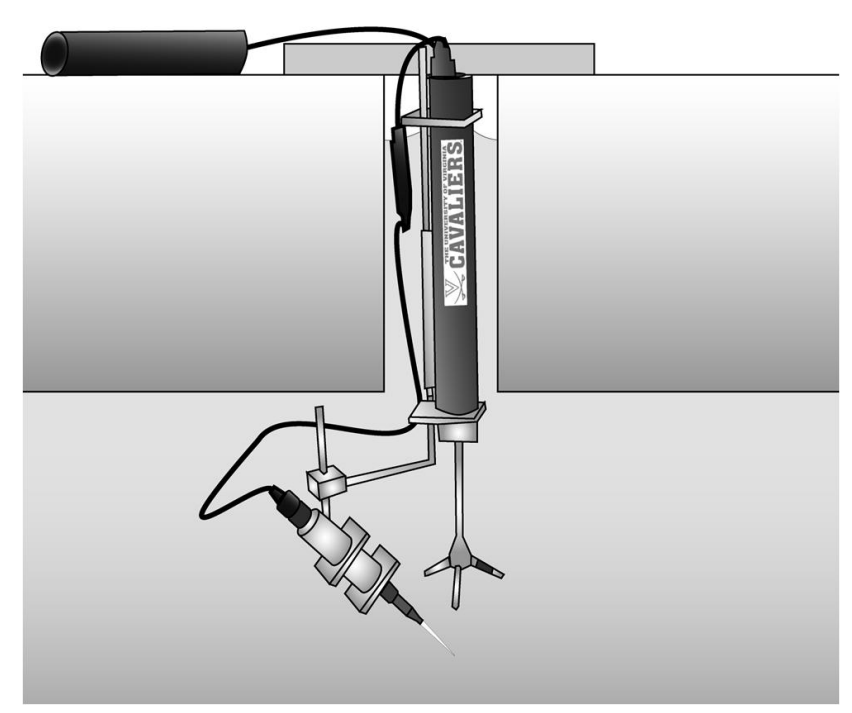

Fig. 1. Eddy correlation instrument deployed under sea-ice through a rectangular-shaped hole and secured with a $\mathrm{T}$ bar at the ice-air interface. The instrument may freeze into the ice but the power supply (top left) and communication port (top center) remained accessible from above.

USA) (Crusius et al., 2008). Damage to the conductivity sensors prevented simultaneous measurement of the salt flux.

The systems were positioned under the sea-ice by lowering them through a 0.25 by $0.60 \mathrm{~m}$ rectangular hole (Fig. 1). This new deployment tactic, compared to traditional tripod mounted systems, was very simple and did not require any diver support. The ADV and scalar sensors were mounted to a stainless steel $\mathrm{T}$ rod with the sensors positioned at the edge of the ADV's $\sim 1 \mathrm{~cm}^{3}$ measuring volume that was located $22 \mathrm{~cm}$ below the ice-water interface.

Water velocity ( $x, y$, and $z$ components), time, $\mathrm{O}_{2}$ concentration and temperature were recorded by the ADVs at a frequency of $64 \mathrm{~Hz}$ in intervals of $0.25 \mathrm{~h}$. Total measurement periods were typically $24 \mathrm{~h}$ long to capture diurnal fluctuations. An $\mathrm{O}_{2}$ optode (Hach, USA) measured the mean $\mathrm{O}_{2}$ concentration as a calibration check of the Clark-type $\mathrm{O}_{2}$ microsensors. Photosynthetically active radiation (PAR) was determined using a self-contained cosine-corrected integrating PAR logger (Odyssey, New Zealand) which was deployed just below the ice-water interface.

\subsection{Data analysis}

Fluxes of $\mathrm{O}_{2}$ and heat across the ice-water interface were calculated from high resolution measurements of the vertical velocity and either the $\mathrm{O}_{2}$ concentration or temperature as:

$\overline{\text { Flux }}=\overline{u_{\mathrm{z}}^{\prime} C^{\prime}}$

where $u_{\mathrm{z}}^{\prime}$ is the instantaneous fluctuating component of the vertical velocity, $C^{\prime}$ is the instantaneous fluctuating component of the $\mathrm{O}_{2}$ concentration or temperature, and the bars symbolize averaging over time (Berg et al., 2003). The fluctuating components were separated from the means by Reynolds decomposition as $u_{\mathrm{z}}^{\prime}=u_{\mathrm{z}}-\overline{u_{\mathrm{z}}}$ and $C^{\prime}=\mathrm{C}-\bar{C}$ where $u_{\mathrm{z}}$ and $\mathrm{C}$ are the instantaneous measurements, and the means $\left(\overline{u_{\mathrm{z}}}\right.$ and $\left.\bar{C}\right)$ were determined by linear least squares fits (linear detrending) over each $0.25 \mathrm{~h}$ interval (Berg et al., 2009). The three-dimensional velocity field was rotated to orient the $\mathrm{x}$-axis into the mean flow direction and to bring the mean vertical velocities to zero to correct for any sensor tilt. The $\mathrm{O}_{2}$ concentration, temperature, and velocities in each interval were examined carefully for anomalous variations due to sensor malfunctions caused by disturbances of the sensors, for example due to debris floating in the water. Furthermore, the mean current velocity, the cumulative flux $\left(\mathrm{O}_{2}\right.$ or heat), the spectra (vertical velocity and heat or $\mathrm{O}_{2}$ concentration), and the cospectra (vertical velocity vs. heat or $\mathrm{O}_{2}$ concentration) were used to identify periods with welldeveloped turbulence under the ice where trustworthy eddy fluxes could be determined (see Results and Discussion).

The rate of ice melt $(h)$ was calculated from the temperature flux (Eq. 1) as:

$h=\frac{\overline{u_{\mathrm{z}}^{\prime} T^{\prime}} c_{\mathrm{pw}} \rho_{\mathrm{w}}}{\Delta H_{\mathrm{f}} \rho_{\mathrm{i}}}$

where $c_{\mathrm{pw}}$ is the specific heat capacity of seawater, $\rho_{\mathrm{w}}$ is the density of seawater, $\Delta H_{\mathrm{f}}$ is the specific heat of fusion of ice, and $\rho_{\mathrm{i}}$ is the density of the ice. The numerator of Eq. (2) constitutes the heat flux. For the purposes of this first order calculation of the melt rate we assumed the conduction of heat up through the ice was negligible. This assumption makes the calculated rates represent an upper limit for ice melt. Furthermore, due to the difficulty in determining the $\mathrm{O}_{2}$ concentration of the melt water, an $\mathrm{O}_{2}$ flux due to ice melt was determined assuming that the melt water from sea-ice was anoxic. This also results in an overestimate of the $\mathrm{O}_{2}$ flux due to ice melt as bulk ice $\mathrm{O}_{2}$ concentrations were found to range between 40 and $280 \mu \mathrm{mol} \mathrm{L}^{-1}$ at a bulk salinity of 4.6 during the campaign (Tison et al., unpublished data). Assuming a small, constant contribution of ice melt to the total $\mathrm{O}_{2}$ exchange rate, a constant respiration rate, and that $\mathrm{O}_{2}$ metabolism occured predominantly at the ice-water interface, simple relationships between measured $\mathrm{O}_{2}$ fluxes, rates of $\mathrm{O}_{2}$ production $(P)$ and respiration $(R)$, and the irradiance were developed:

$\mathrm{O}_{2}$ flux $=P-R$

$P=P_{0}\left(1-\exp ^{\left(-I / I_{\mathrm{k}}\right)}\right)$

where $P_{0}$ is the maximum primary production rate in the photosynthesis to irradiance $(P / I)$ curve for sea-ice algae, $I$ is irradiance and $I_{\mathrm{k}}$ is the photoadaptation parameter or the irradiance level at which photosynthesizing organisms begin to become saturated with light (Platt et al., 1980; Smith et al., 1988; Suzuki et al., 1997). 

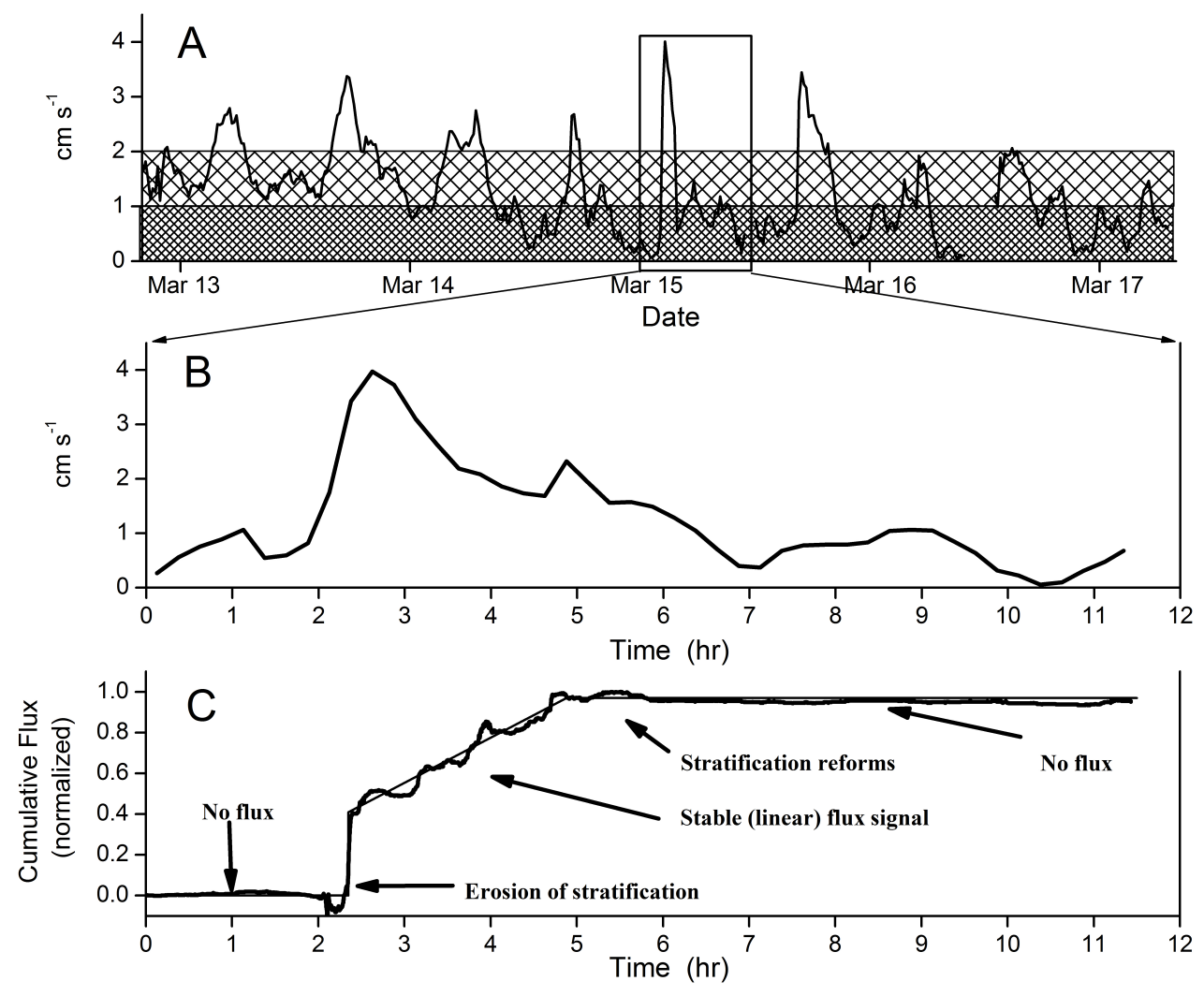

Fig. 2. (A) shows the mean current velocity measured $22 \mathrm{~cm}$ below the ice-water interface over $4.5 \mathrm{~d}$. The dark shaded region $\left(<1 \mathrm{~cm} \mathrm{~s}{ }^{-1}\right)$ represents conditions where density stratification in the water column appeared to be persistently present while the lightly shaded region (1$2 \mathrm{~cm} \mathrm{~s}^{-1}$ ) represents conditions where stratification was occasionally observed. The presence of stratification was evaluated by examining the mean velocity and the stability and linearity of the cumulative flux signal. (B) shows a $12 \mathrm{~h}$ segment of the velocity data in (A). (C) shows that during this segment the flux signal was strongly dependent on current velocity. The magnitude of the vertical rise at hour 2.3 , when stratification eroded due to an increase in velocity, was not indicative of any true flux and therefore was not included in the flux measurements.

\section{Results}

During periods of low current flow, vertical turbulent mixing was not consistently adequate to prevent density stratification from forming immediately below the ice. However, well-developed turbulence was generally found at current velocities greater than $1-2 \mathrm{~cm} \mathrm{~s}^{-1}$. Figure 2 shows an example of how current velocity changed the turbulent transport and mixing under ice. At low current velocities there was little or no vertical mixing, which resulted in the formation of density stratification. As the velocity increased there was a point when this stratification was eroded and allowed the water column immediately below the ice to be mixed. The onset of mixing events were evident in large $\mathrm{O}_{2}$ and temperature fluctuations and were not used in the flux calculations because of the incompatibility with linear detrending over these periods of widely fluctuating $\mathrm{O}_{2}$ and temperature signals. Furthermore, the mixing of the stratified layer was not indicative of the actual flux at that point in time, and the period leading up to this integrated signal is poorly constrained. The erosion of stratification was followed by periods of stable and linear cumulative flux signals that were suitable for flux determination. Finally, as the velocity and associated turbulence decreased, the stratification was re-established. Stratification prevented the determination of fluxes $61 \%$ of the total deployment time.

Stratified conditions were identified by examining the current velocity and the corresponding cumulative flux signal. Under low flow conditions the cumulative flux became highly nonlinear and erratic, indicating a weak flux signal. Under high flow conditions a consistent and linear trend in the cumulative flux indicated a strong flux signal. Wellmixed conditions where fluxes could be accurately determined were found $26 \%$ of the time. Due to broken or malfunctioning sensors, fluxes were not determined during the remaining $13 \%$ of the time despite likely turbulent conditions (i.e. velocity $>2 \mathrm{~cm} \mathrm{~s}^{-1}$ ). Unstratified conditions were further examined in the frequency domain through the vertical velocity spectrum, where fully developed turbulence was indicated by a characteristic $-5 / 3$ slope (Fig. 3a) (Kundu and Cohen, 2008). Similarly the $\mathrm{O}_{2}$ spectrum shows an initial $-5 / 3$ slope at lower frequencies and the expected -1 slope 

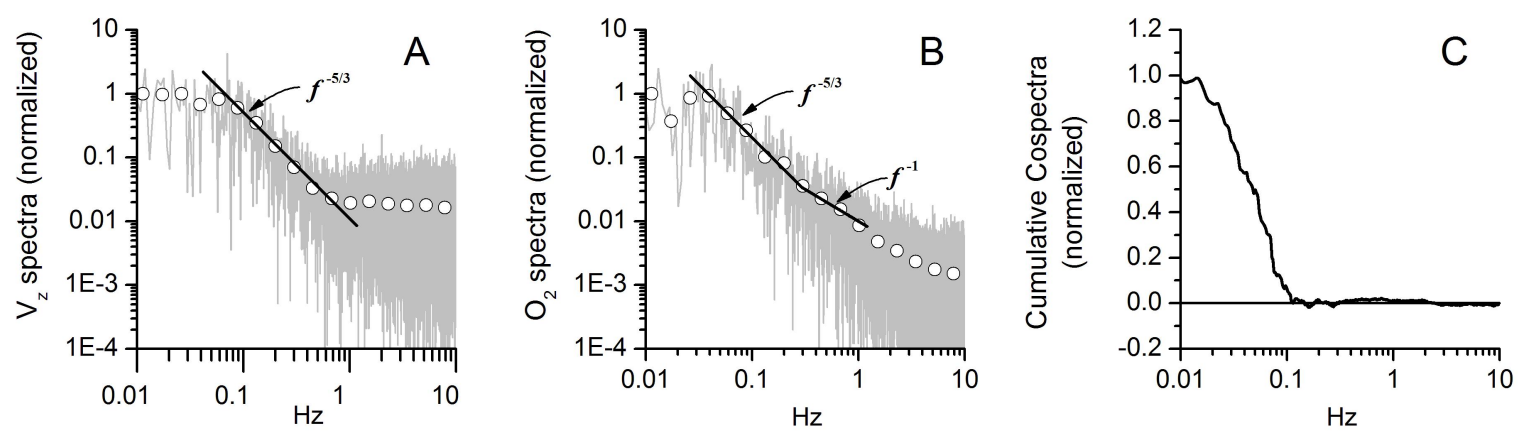

Fig. 3. Typical spectra for current-driven turbulent flow under sea-ice (current velocity: $1.86 \mathrm{~cm} \mathrm{~s}^{-1}$ ). (A) and (B) show the normalized spectra of the vertical velocity and the $\mathrm{O}_{2}$ concentration, respectively. The $-5 / 3$ slopes are indicative of well-developed turbulence and represent the inertial subrange where inertial forces dominate transport, according to Kolmogorov's theory of turbulence. The -1 slope at higher frequencies in the $\mathrm{O}_{2}$ spectrum indicates the transport of $\mathrm{O}_{2}$ by both viscous and convective forces. (C) shows the normalized cumulative cospectrum of vertical velocity and $\mathrm{O}_{2}$ and revealed that eddies with frequencies $<\sim 0.1 \mathrm{~Hz}$ contributed most of the vertical turbulence-driven $\mathrm{O}_{2}$ transport.

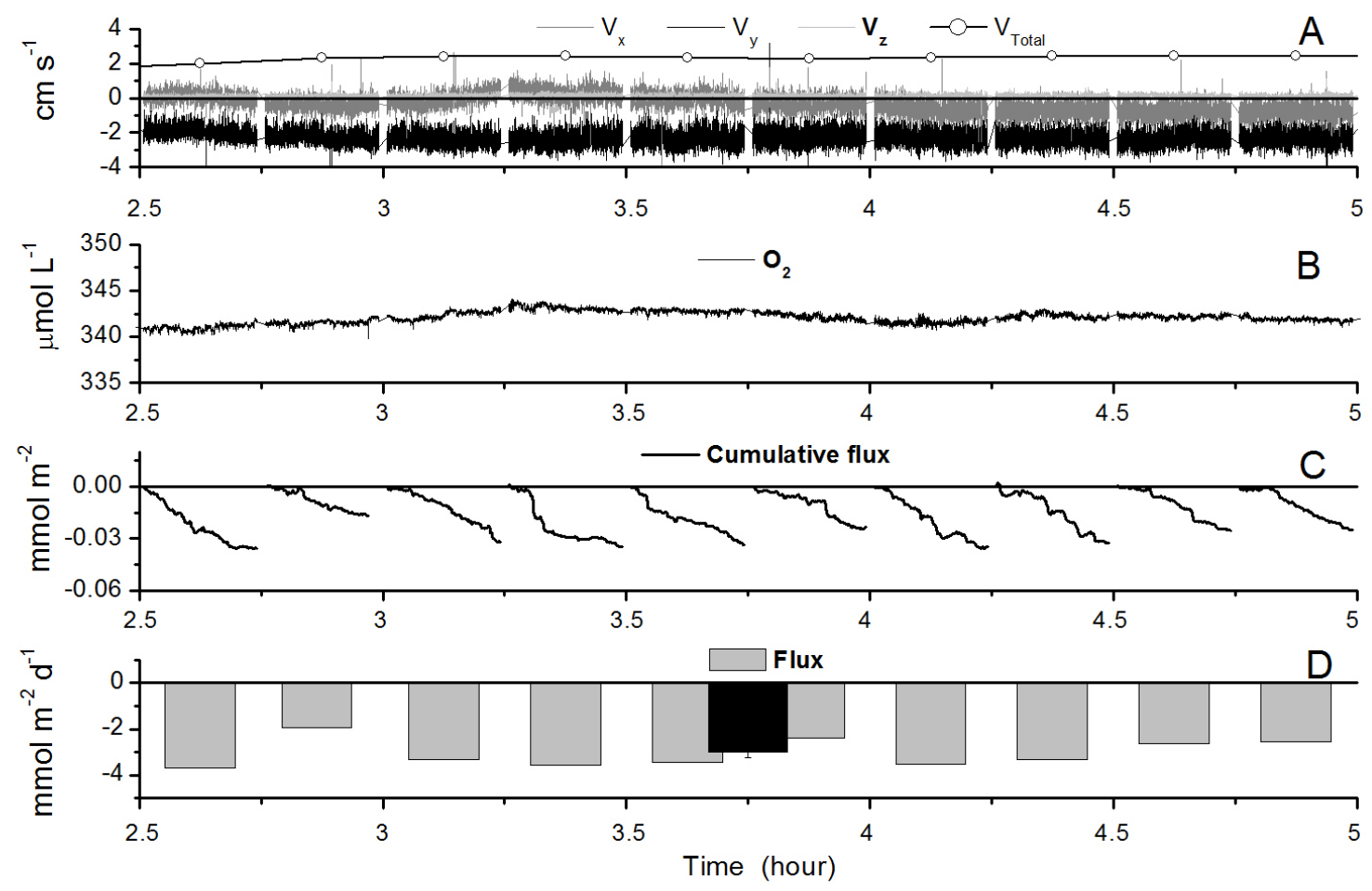

Fig. 4. A typical example of eddy correlation data measured in $0.25 \mathrm{~h}$ intervals $22 \mathrm{~cm}$ below the ice-water interface through $2.5 \mathrm{~h}$. (A) shows the $x, y$, and $z$ components of the velocity at $16 \mathrm{~Hz}$ and the mean current velocity. (B) shows the corresponding $\mathrm{O}_{2}$ concentration at $16 \mathrm{~Hz}$. (C) shows the cumulative flux calculated for each $0.25 \mathrm{~h}$ interval and (D) is the average $\mathrm{O}_{2}$ flux for each $0.25 \mathrm{~h}$ interval. A negative flux is a net flux of $\mathrm{O}_{2}$ towards the ice. The black bar is the $\mathrm{O}_{2}$ flux averaged across $2.5 \mathrm{~h}$ where the error bar represents the standard error.

at higher frequencies where viscous forces gain importance (Fig. 3b) (Kundu and Cohen, 2008). The normalized cumulative cospectrum of the vertical velocity and $\mathrm{O}_{2}$ concentration (Fig. 3c) also shows the typical fingerprint of turbulent transport where eddies with frequencies less than $0.1 \mathrm{~Hz}$ dominate the vertical turbulent transport of $\mathrm{O}_{2}$. Under well-mixed conditions the fluxes of $\mathrm{O}_{2}$ and heat were highly reproducible.
For example, Fig. 4 shows a typical example of $\mathrm{O}_{2}$ eddy correlation data at night over $2.5 \mathrm{~h}$, with an average flux of $-2.99 \pm 0.26 \mathrm{mmol} \mathrm{m}^{-2} \mathrm{~d}^{-1}(\mathrm{SE}, n=10)$ where a negative flux is a net flux of $\mathrm{O}_{2}$ towards the ice. The consistent and linear cumulative fluxes indicate a strong flux signal (Fig. 4c).

All trustworthy mean $\mathrm{O}_{2}$ fluxes for the entire study period are shown in Fig. 5. The smallest net $\mathrm{O}_{2}$ flux towards the 

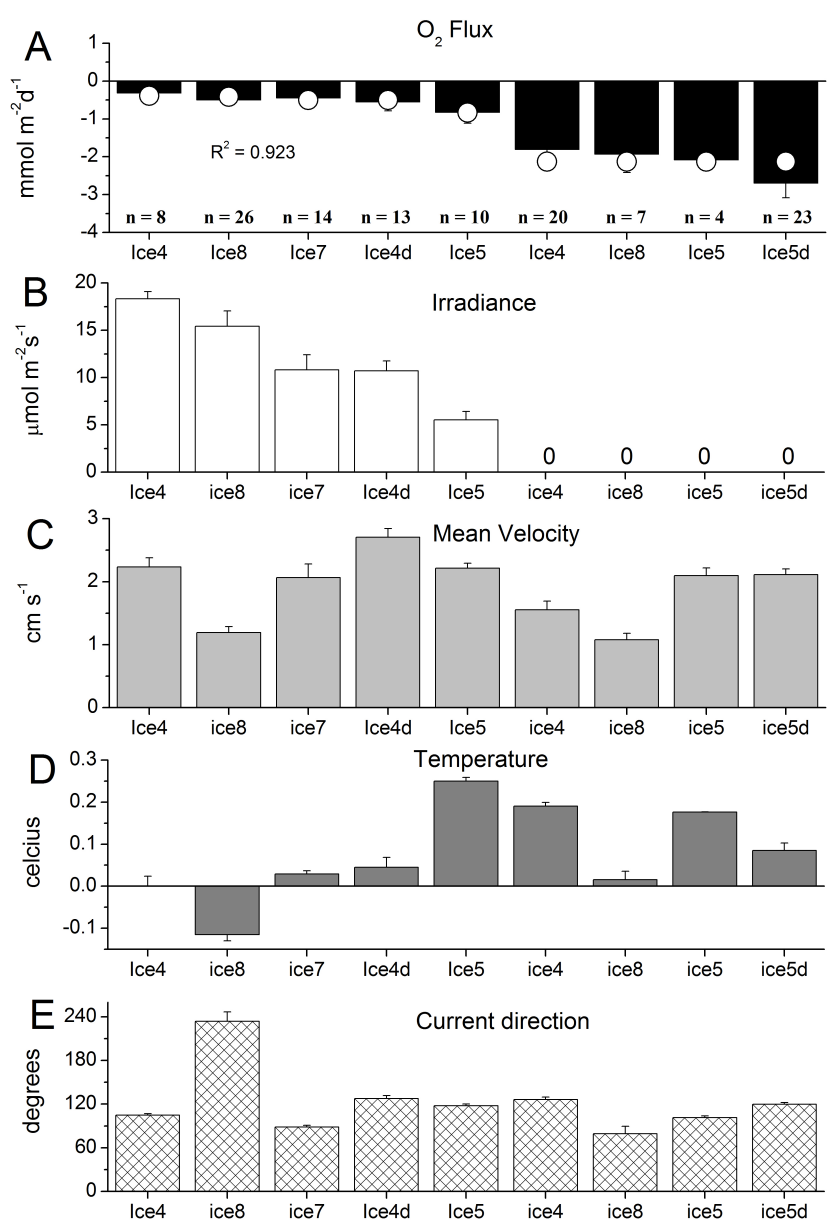

Fig. 5. Averaged $\mathrm{O}_{2}$ fluxes for periods with well-developed turbulence under the ice-water interface are shown in (A), where $n$ represents the number of $0.25 \mathrm{~h}$ intervals included in each average. The open circles in (A) represent the flux determined by fitting Eqs. 3 and 4 simultaneously $\left(R^{2}=0.923\right)$ to the averaged fluxes. B, C, D, and $\mathbf{E}$ show the averages of under ice irradiance, mean current velocity, temperature and current angle over each period, respectively. All error bars represent standard errors.

ice occurred during peak irradiance. No correlation between current direction and the $\mathrm{O}_{2}$ flux was found $\left(R^{2}=0.021, p\right.$ $=0.816, n=123)$. The white circles in Fig. 5a are the model results determined by simultaneously fitting Eqs. 3 and $4\left(R^{2}\right.$ $=0.923)$ to the mean fluxes as described below.

The $P / I$ curve (Eq. 4) resulted from the fitting of the eddy correlation data in Fig. 5, with $R$ being the average $\mathrm{O}_{2}$ flux in the dark $\left(R^{2}=0.923\right.$, Fig. 5). The maximum $P$ rate was $1.76 \pm 0.27 \mathrm{mmol} \mathrm{O}_{2} \mathrm{~m}^{-2} \mathrm{~d}^{-1}$ (SE, $n=$ 8) and $I_{\mathrm{k}}$ was $4.2 \mu \mathrm{mol}$ photons $\mathrm{m}^{-2} \mathrm{~s}^{-1}$ (based on irradiance measured just below the ice-water interface). Using Eqs. 3 and 4 and the measured light values, $0.25 \mathrm{~h} \mathrm{O}_{2}$ exchange rates were calculated across 4 days of the study period (Fig. 7). From these model results the daily values of $R$, gross primary production (GPP), and net ecosystem

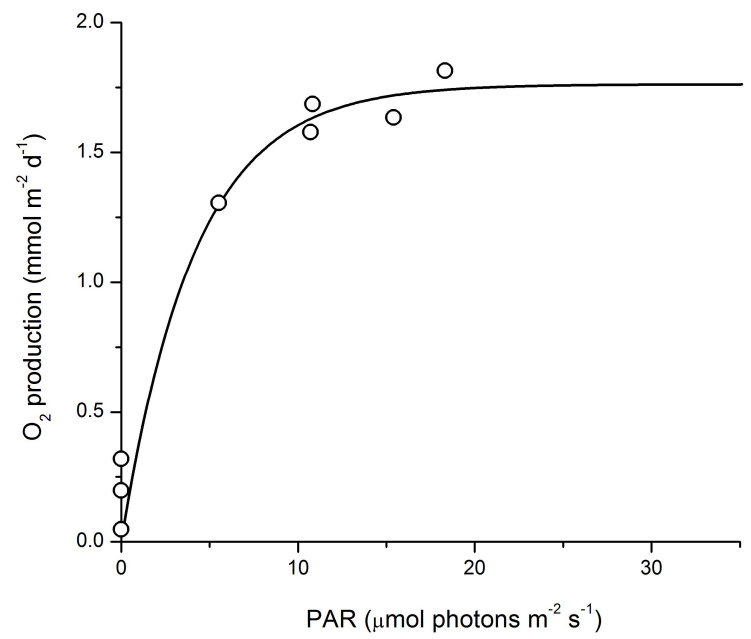

Fig. 6. $P / I$ curve calculated by fitting Eqs. 3 and 4 simultaneously $\left(R^{2}=0.923\right)$ to the averaged $\mathrm{O}_{2}$ fluxes in Fig. 5a. The open circles represent the GPP determined from the averaged fluxes in Fig. 5A. This $P / I$ curve had an $I_{\mathrm{k}}$ value of $4.2 \mu \mathrm{mol}$ photons $\mathrm{m}^{-2} \mathrm{~s}^{-1}$ which represents the point where light saturation begins to occur.

metabolism (NEM) were calculated with the rates weighted by the hours of daylight and darkness and assuming that respiration was the same day and night. This resulted in a value of $R$ of $-2.13 \mathrm{mmol} \mathrm{O}_{2} \mathrm{~m}^{-2} \mathrm{~d}^{-1}$ while GPP averaged $0.69 \pm 0.02 \mathrm{mmol} \mathrm{O}_{2} \mathrm{~m}^{-2} \mathrm{~d}^{-1}(\mathrm{SE}, n=4)$, and NEM averaged $-1.45 \pm 0.02 \mathrm{mmol} \mathrm{O}_{2} \mathrm{~m}^{-2} \mathrm{~d}^{-1}(\mathrm{SE}, n=4)$. Light saturation (based on $I_{\mathrm{k}}$ ) occurred at an average of $1.47 \pm 0.09 \mathrm{~h}$ (SE, $n=8$ ) after first light and before darkness. With an average day length of $11.69 \pm 0.24 \mathrm{~h}(\mathrm{SE}, n=4)$ the bottom ice algal communities were therefore light saturated for $75 \%$ of the day.

The mean heat flux was $2.83 \pm 0.30 \mathrm{~W} \mathrm{~m}^{-2}$ (SE, $n$ $=31$, giving a calculated rate of ice melt (Eq. 2) of $0.80 \pm 0.09 \mathrm{~mm} \mathrm{~d}^{-1}$ (SE, $n=31$ ). The mean observed temperature of seawater during the measuring period was $-0.05^{\circ} \mathrm{C}$ and the salinity 33 . The specific heat capacity of the seawater was assumed to be $3.999 \mathrm{~J} \mathrm{~g}^{-1}{ }^{\circ} \mathrm{C}^{-1}$ and the density was assumed to be $1.026 \mathrm{~g} \mathrm{~cm}^{-3}$ (Fofonoff and Millard, 1983). In our first-order calculation of melting rates we assumed that the entire heat flux towards the sea-ice was used to melt pure ice, and thus, neglected any portion of the flux that might have been lost by heat conduction up into the ice interior. As explained above, this leads to an overestimation of the ice melt rate and of the $\mathrm{O}_{2}$ flux associated with it. Based on this assumption we used a heat of fusion for pure ice of $333.6 \mathrm{~J} \mathrm{~g}^{-1}$ (Harvey, 2010) and a density of ice of $0.917 \mathrm{~g} \mathrm{~cm}^{-3}$ (Eicken, 2003). The average ice melt rates shown in Fig. 8 varies from $0.49 \pm 0.11$ (SE, $n$ =6) to $0.99 \pm 0.25 \mathrm{~mm} \mathrm{~d}^{-1}$ (SE, $\left.n=8\right)$. The ice melt rates were not significantly different between each period $\left(F_{4}=\right.$ $2.040, p=0.111$ at 0.01 level). There were no correlations between the observed $0.25 \mathrm{~h}$ heat fluxes and velocity $\left(R^{2}=\right.$ 

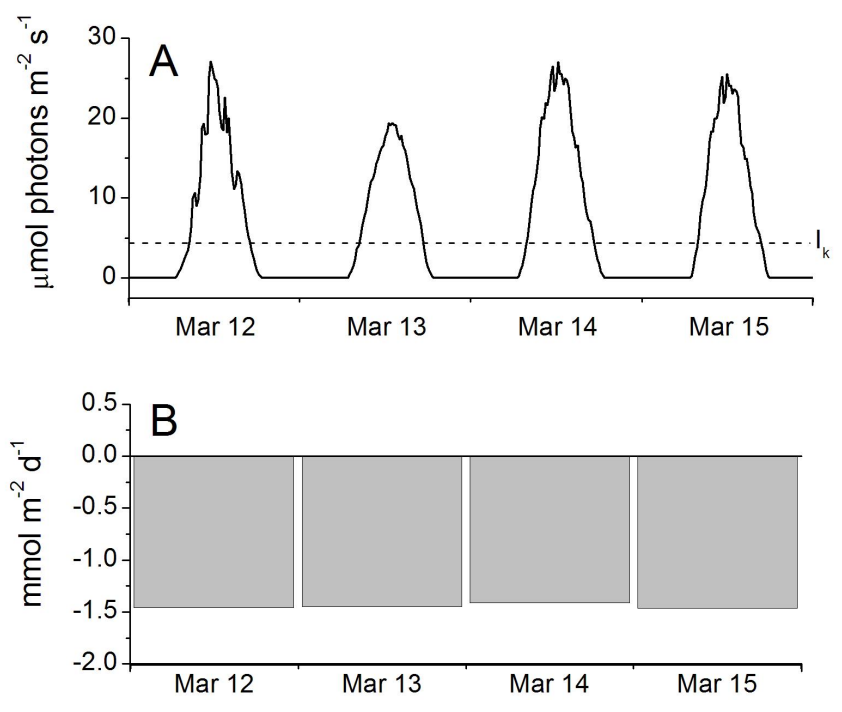

Fig. 7. (A) shows four days of irradiance measured immediately below the sea-ice. The dashed line is the $I_{\mathrm{k}}$ value determined from the $P / I$ curve and indicates that light saturation is present over much of the daylight hours. (B) shows the $24 \mathrm{~h}$ integrated $\mathrm{O}_{2}$ fluxes calculated from the irradiances in (A) and Eqs. 3 and 4. The small variations between these daily $\mathrm{O}_{2}$ fluxes resulted from the ice algae being light saturated over most of the day.

$0.002, p=0.833)$, temperature $\left(R^{2}=0.022, p=0.450\right)$, light $\left(R^{2}=0.016, p=0.492\right)$, or current direction $\left(R^{2}=0.001, p\right.$ $=0.866)$. The $\mathrm{O}_{2}$ flux that was calculated based on the ice melt rates, through the melting of de-oxygenated ice, averaged $-0.28 \pm 0.03 \mathrm{mmol} \mathrm{O}_{2} \mathrm{~m}^{-2} \mathrm{~d}^{-1}(\mathrm{SE}, n=31)$. This flux amounts to less than $13 \%$ of the daily $R$ rate derived from fitting Eqs. 3 and 4 to the data in Fig. 5.

The footprint, or the area of the ice surface that contributes $90 \%$ of the measured flux (Fig. 9), was calculated from estimated values of the friction velocity $\left(\mathrm{u}^{*}\right)$, the surface roughness $\left(z_{0}\right)$, and the measuring height as described by Berg et al., (2007). This first order calculation revealed a value of $\mathrm{u}^{*}$ of $0.098 \pm 0.007 \mathrm{~cm} \mathrm{~s}^{-1}$ (SE, $n=20$ ) and a hydraulically smooth ice surface with a $z_{\mathrm{o}}$ of $0.023 \pm 0.002 \mathrm{~cm}$ (SE, $n=$ 20) (see Berg et al., 2007 for details). The oval shaped footprint was about $2.8 \mathrm{~m}$ wide by $67 \mathrm{~m}$ long with a point of maximum flux contribution at $3.2 \mathrm{~m}$ upstream from the eddy correlation instrument (Fig. 9).

The level of anisotropy in the turbulent flow below the seaice, as reflected in the ratios between the eddy diffusivities $\left(E_{\mathrm{x}}, E_{\mathrm{y}}\right.$, and $\left.E_{\mathrm{z}}\right)$ in the $\mathrm{x}, \mathrm{y}$, and $\mathrm{z}$ directions, was estimated as described by Berg et al., (2007) (Fig. 10). Anisotropy was clearly evident $\left(E_{\mathrm{x}} / E_{\mathrm{Z}}=6.2 \pm 1.0, E_{\mathrm{y}} / E_{\mathrm{Z}}=3.8 \pm 0.5\right.$, $\left.E_{\mathrm{Z}} / E_{\mathrm{Z}}=1 \pm 0.0 ; \mathrm{SE}, n=5\right)$.

\section{Discussion}

The eddy correlation technique is in many respects superior to traditional flux methods (Berg et al., 2003; Kuwae et al., 2006; Berg and Huettel, 2008) and this study conducted at the ice-water interface further exhibits the adaptability and advantages of the technique. The first measurements of $\mathrm{O}_{2}$ eddy correlation fluxes at the ice-water interface presented here are controlled by ice melt, and to a much larger extent, the biological activity of the microbial communities. However, the ice-water interface also produces conditions that must be addressed when sampling eddy correlation ice-water fluxes such as low current velocities, density stratifications, and instrument deployment. Despite this, the eddy correlation technique is well suited for flux measurements at the ice-water interface and has previously been applied and validated for momentum, heat, and salt fluxes (McPhee, 1992; Shirasawa et al., 1997; Widell et al., 2006; McPhee et al., 2008).

Measured $\mathrm{O}_{2}$ exchange rates across the ice-water interface do not directly represent primary production and respiration, as physical processes may also contribute to the exchange during periods of rapid freezing or melting. These physical processes include the release of $\mathrm{O}_{2}$ supersaturated brine during freezing or the release of $\mathrm{O}_{2}$ undersaturated water during melting (Glud et al., 2002; Rysgaard et al., 2008). Although these physical processes only contributed a minor portion of the total $\mathrm{O}_{2}$ flux in this study due to very low melt rates, this will not always be the case. Heat fluxes can be measured and translated into melting rates, but the relevant ice $\mathrm{O}_{2}$ concentration, as well as the fraction of the measured heat flux that is conducted up into the ice rather than melting it, must be known to accurately calculate the associated $\mathrm{O}_{2}$ flux.

The release of melt or brine flows may also cause stratification immediately below the ice and therefore a careful examination of the state of turbulence and mixing below the ice-water interface is required. The eddy correlation technique assumes that the dominant form of vertical transport is turbulent mixing. Therefore, the technique may produce inaccurate results at very low current velocities when there is also insufficient turbulence. Ice freeze and melt may also cause convection to occur, which has been reported as a problem for measuring $\mathrm{O}_{2}$ fluxes from profiles generated with microelectrodes (Glud et al., 2002; McMinn et al., 2010). However, with the eddy correlation technique these convective processes are included in measurements, and with the concurrent determination of ice melt rates we can estimate the net $\mathrm{O}_{2}$ flux due to primary production and respiration.

The lack of vertical mixing under low-flow conditions allowed density stratification to build up immediately below the ice due to ice melt (Fig. 2). This stratification caused the effects of the flux to be confined within the stratified layer near the ice, as evidenced by the large pulse in the signal when the stratification was later eroded (Fig. 2). As a result, accurate fluxes could only be derived when the vertical 

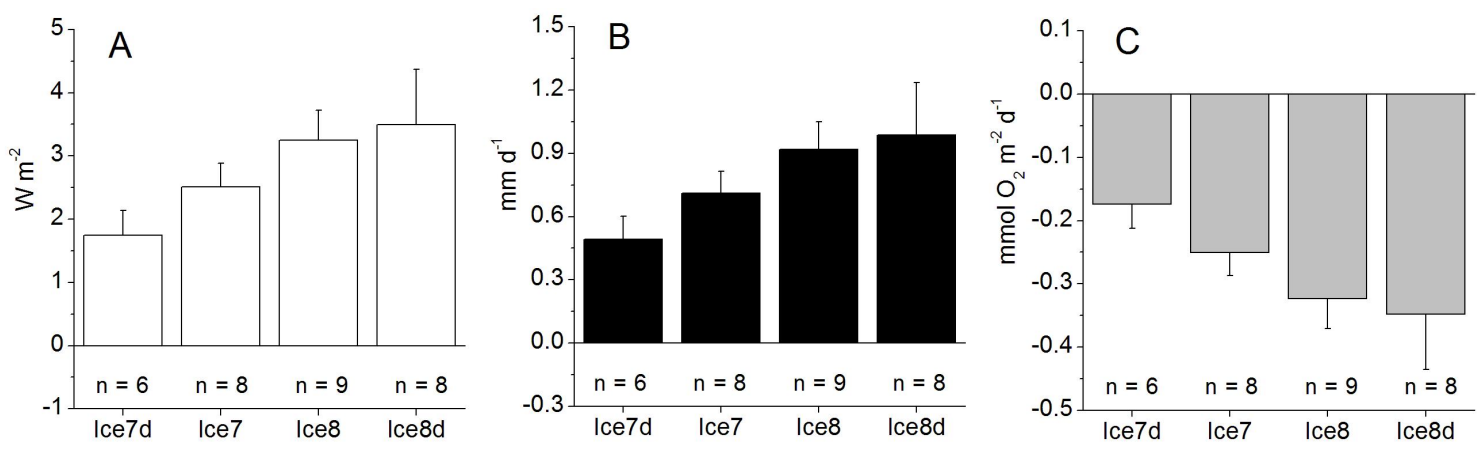

Fig. 8. (A) shows the averaged heat fluxes for periods with well-developed turbulence under the ice-water interface. The maximum potential ice melt rate derived from the heat flux is shown in (B) and the maximum $\mathrm{O}_{2}$ flux calculated from this melt rate is shown in (C). The $n$ represents the number of $0.25 \mathrm{~h}$ measuring periods and error bars represent standard errors.

mixing due to turbulent flow was strong enough to erode and prevent density stratifications. The mean current velocity provided a benchmark for determining when stratification would occur, and this was further evaluated by examining the cumulative flux, as little or no flux was recorded during periods of weak turbulence, while stable and linear cumulative fluxes were derived during periods of well-developed turbulence (Fig. 2). The presence of well-developed turbulence was also examined through the spectra of the vertical velocity and the $\mathrm{O}_{2}$ concentration (Fig. $3 \mathrm{a}$ and b). The presence of the inertial sub-range with a characteristic $-5 / 3$ slope is indicative of well-developed turbulence (Kundu and Cohen, 2008). The cospectrum of the vertical velocity and $\mathrm{O}_{2}$ concentration was also examined to determine the frequency of the turbulent eddies that contributed to the flux. The example shown in Fig. 3c indicated that the contributing eddies had frequencies less than $0.1 \mathrm{~Hz}$, and that larger eddies, with a significant portion below the initial sub-range, were responsible for the vertical transport.

An examination of the eddy diffusivities (Fig. 10) revealed that the turbulent mixing below the ice was clearly anisotropic as expected in flows near solid boundaries. The relatively small ratio between the longitudinal $\left(E_{\mathrm{X}}\right)$ and vertical $\left(E_{\mathrm{z}}\right)$ eddy diffusivity of 6:1 suggests that the water column was fully mixed, at least within the upper meters below the ice-water interface. For comparison, a ratio of 12:1 was found for a $1 \mathrm{~m}$ deep river that was fully vertically mixed (Berg et al., 2007). If stratification had been present under the ice it would reduce the vertical mixing and therefore give a much larger ratio. However, we stress that both the strength and depth of the density stratification are highly dynamic properties that change across time, and that intermittent lowflow conditions represent a challenge for eddy correlation measurements at the ice-water interface.

The footprint of the eddy correlation technique (Fig. 9) is very large compared to that of other flux methods (Berg et al., 2007) and is expected to integrate most variability commonly observed at the ice-water interface (McMinn and Ashworth,
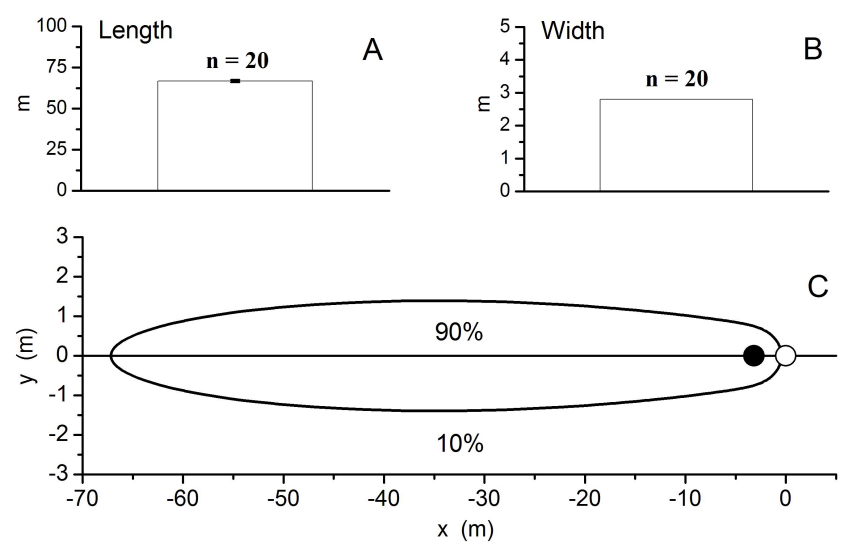

Fig. 9. The estimated length, width and shape of the eddy correlation footprint are shown in $(\mathbf{A}, \mathbf{B})$, and $(\mathbf{C})$, respectively. The error bars represent standard error and $n$ represents the number of $0.25 \mathrm{~h}$ measuring periods. (C) shows the footprint or the area that contributes $90 \%$ of the flux (note the difference in axis scales). The open circle represents location of the eddy correlation instrument and the solid circle indicates the point of maximum flux contribution.

1998; Rysgaard et al., 2001). It has been suggested that to include all horizontal variations in light, algal biomass and algal activity it is necessary to measure across distances of 20 to $100 \mathrm{~m}$ as dictated by variations in light availability below melting ponds and snow drifts (Gosselin et al., 1986; Rysgaard et al., 2001; Søgaard et al., 2010). Figure 9 shows the size of the footprint to be over $60 \mathrm{~m}$ long, and therefore it integrates over most of this variability. However, given the narrow width of the footprint its composition will change with even a small change in current direction. This variability can easily be investigated by examining the correlations between the fluxes and the current direction, and in this study none were found $\left(R^{2}=0.021, n=166\right)$. 


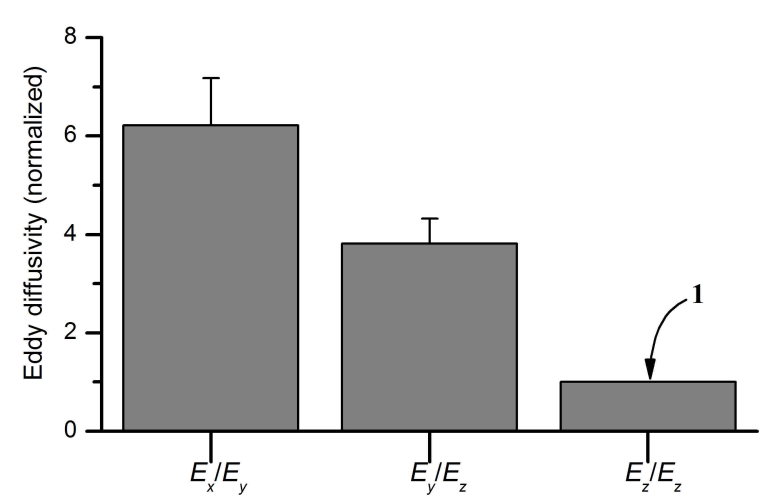

Fig. 10. Level of anisotropy in the turbulent flow below the sea-ice, as reflected in the ratios between the eddy diffusivities $\left(E_{\mathrm{X}}, E_{\mathrm{y}}\right.$, and $E_{\mathrm{Z}}$ ) in the $\mathrm{x}, \mathrm{y}$, and $\mathrm{z}$ directions.

Given the small difference between the mean seawater temperature and its freezing point, low rates of ice melt were expected. Throughout the study period low ice melt was observed (Fig. 8), and the measured $\mathrm{O}_{2}$ exchange rates indicated a net consumption of $\mathrm{O}_{2}$ (Fig. 5), which represent both the consumption by organisms and to a lesser degree the melting of deoxygenated ice crystals (Glud et al., 2002; Rysgaard and Glud, 2004). Specifically, the $\mathrm{O}_{2}$ flux associated with ice melting was shown to be less than $13 \%$ of the average daily respiration rate (see Figs. 5 and 8). This calculated potential $\mathrm{O}_{2}$ flux due to melting assumes that all of the heat flux results in ice melting and that melt water is anoxic. The $\mathrm{O}_{2}$ concentration of water released during melting remains an uncertainty, especially considering that brine channels may advect $\mathrm{O}_{2}$ depleted or enriched water from anywhere within the ice. The ice also had a significantly lower temperature than that of the water column (McGinnis et al., 2012) and therefore the conduction of heat into the colder ice likely accounted for some heat flux without causing melt. Considering these uncertainties we were only able to put an upper limit on how much ice melt could affect the total $\mathrm{O}_{2}$ flux. Thus, this maximum $\mathrm{O}_{2}$ flux due to ice melt cannot account for any significant differences in fluxes during the study period. However, it is expected that physical processes during rapid ice growth and melting during other periods of the year may greatly affect the $\mathrm{O}_{2}$ exchange and could potentially exceed the biological contribution. The $\mathrm{O}_{2}$ flux showed a strong correlation to light (Fig. 5) as GPP reduced the net flux of $\mathrm{O}_{2}$ toward the ice during the day. However, at all times the ice was net heterotrophic, which has been observed by others (Rysgaard and Glud, 2004; Rysgaard et al., 2008). The calculation of GPP uses the standard convention that the daytime and nighttime respiration rates are equal, as it is not possible to separate the two. However, this may lead to an underestimate of daytime respiration due to the stimulation of respiration by the release of photosynthates (Fenchel and Glud, 2000; Glud et al., 2009).
The $P / I$ curve established through model fitting (Figs. 5 and 6) revealed that the ice algae were well adapted to low light conditions with an $I_{\mathrm{k}}$ of about $4 \mu \mathrm{mol}$ photons $\mathrm{m}^{-2} \mathrm{~s}^{-1}$. This is supported by many other studies that show sea-ice algae to be low-light adapted with values of $I_{\mathrm{k}}$ between 0.5 and $35 \mu \mathrm{mol}$ photons $\mathrm{m}^{-2} \mathrm{~s}^{-1}$ (Cota, 1985; Kuhl et al., 2001; Rysgaard et al., 2001). Based on continuously measured light levels under the ice and the $I_{\mathrm{k}}$ value, the primary producers appear to be light saturated for $75 \%$ of the day below the snow-covered ice. From the PAR measurements and the model fit to the derived $\mathrm{O}_{2}$ fluxes (Fig. $5, R^{2}=0.923$ ) it was possible to estimate the net $\mathrm{O}_{2}$ flux throughout several days including periods of insufficient turbulent mixing (Fig. 7). Because the primary producers were light saturated for most of the day, other variables could potentially control ice algae production. Gradinger (2009) found that nutrients were the major limiting factors for sea-ice algae production while others suggest that transient photoinhibition could occur at higher PAR levels (Kuhl et al., 2001; Rysgaard et al., 2001) or that high salinities may reduce primary production (Mock and Gradinger, 1999; Mock et al., 2003; Manes and Gradinger, 2009).

Our GPP rates are supported by three recent studies at comparable sites in southwest Greenland by Mikkelsen et al., (2008) and Søgaard et al., (2010, 2012) who estimated maximum GPP rates using the ${ }^{14} \mathrm{C}$ tracer method. The first two studies were conducted in March through April and the third was conducted parallel with our eddy correlation measurements at a location approximately $100 \mathrm{~m}$ away from the eddy correlation site. The ${ }^{14} \mathrm{C}$ method is drastically different from the eddy correlation technique because the ice is disturbed by melting the ice cores, the cores cover a much smaller and different ice area, and they are incubated ex situ for a specific time period. However, all three studies gave similar maximum GPP rates of 1.75, 1.39, and $1.46 \mathrm{mmol} \mathrm{O}_{2} \mathrm{~m}^{-2} \mathrm{~d}^{-1}$ (assuming a 1:1 ratio of $\mathrm{C}: \mathrm{O}_{2}$ for comparison purposes), respectively, which compared surprisingly well with our estimate of $1.76 \mathrm{mmol} \mathrm{O}_{2} \mathrm{~m}^{-2} \mathrm{~d}^{-1}$. The average GPP rates in March varied between the studies from $0.07 \mathrm{mmol} \mathrm{O}_{2} \mathrm{~m}^{-2} \mathrm{~d}^{-1}$ (Søgaard et al., 2010) to $1.75 \mathrm{mmol} \mathrm{O}_{2} \mathrm{~m}^{-2} \mathrm{~d}^{-1}$ (Mikkelsen et al., 2008) and our measurement of average GPP falls within this range $(0.69 \mathrm{mmol}$ $\mathrm{O}_{2} \mathrm{~m}^{-2} \mathrm{~d}^{-1}$ ). However, the average GPP rate determined at the same time and location by Søgaard et al., (2012) of $0.30 \mathrm{mmol} \mathrm{O}_{2} \mathrm{~m}^{-2} \mathrm{~d}^{-1}$ was lower than our rate. Given the differences in methods we are not surprised by these differences in the results; a point that is further confirmed by bacterial production rates by Søgaard et al., $(2010,2012)$ using the ${ }^{3} \mathrm{H}$ thymidine incorporation method. The estimated respiration rates from ${ }^{3} \mathrm{H}$ thymidine incubations, which exclude microalgal respiration and involve a number of other assumptions that vary significantly in the literature (see Søgaard et al., 2010), of -0.16 and $-0.21 \mathrm{mmol} \mathrm{O}_{2} \mathrm{~m}^{-2} \mathrm{~d}^{-1}$, respectively, were an order of magnitude less than the respiration rate of $-2.13 \mathrm{mmol} \mathrm{O}_{2} \mathrm{~m}^{-2} \mathrm{~d}^{-1}$ we found. We believe that 
these rates are highly dependent on the method used and that to some degree the differences are caused by the intrusive nature of slurry incubations in altering important parameters such as $\mathrm{O}_{2}$, nutrients, and salinity and their distributions within the ice. Furthermore, tracer incubations and eddy correlation may integrate the activity of different sections of the sea-ice and are conducted over different time scales. These differences need further investigation as they have significant implications for determining carbon turn-over in sea-ice.

In summary, the combined temperature and $\mathrm{O}_{2}$ eddy correlation flux measurements made it possible to evaluate and separate $\mathrm{O}_{2}$ exchange rates at the ice-water interface due to biological production and respiration from those caused by melting. In the future these rates may be further elucidated by eddy correlation salt fluxes for which fast and reliable sensors are available. We see eddy correlation measurements as an important tool in future studies of sea-ice metabolism as they represent the closest we can currently come to truly in situ measurements.

Acknowledgements. This study received financial support from the Danish Agency for Science, Technology and Innovation; the Canada Excellence Research Chair (CERC) program; and the National Science Foundation, Chemical Oceanography, grant OCE-0536431. The study is a part of the Greenland Climate Research Center's activities (GCRC6507).

Edited by: J. Middelburg

\section{References}

Arrigo, K. R.: Primary Production in Sea Ice, in: Sea Ice, An Introduction to its Physics, Chemistry and Biology, edited by: Thomas, D. N. and Dieckmann, G. S., Blackwell Publishing, Oxford, 402 pp., 2003.

Berg, P. and Huettel, M.: Monitoring the seafloor using the noninvasive eddy correlation technique, Oceanogr., 21, 164-167, 2008.

Berg, P., Roy, H., Janssen, F., Meyer, V., Jorgensen, B. B., Huettel, M., and de Beer, D.: Oxygen uptake by aquatic sediments measured with a novel non-invasive eddy correlation technique, Mar. Ecol. Prog. Ser., 261, 75-83, 2003.

Berg, P., Roy, H., and Wiberg, P. L.: Eddy correlation flux measurements: The sediment surface area that contributes to the flux, Limnol. Oceanogr., 52, 1672-1684, 2007.

Berg, P., Glud, R. N., Hume, A., Stahl, H., Oguri, K., Meyer, V., and Kitazato, H.: Eddy correlation measurements of oxygen uptake in deep ocean sediments, Limnol. Oceanogr. Meth., 7, 576-584, 2009.

Brand, A., McGinnis, D. F., Wehrli, B., and Wuest, A.: Intermittent oxygen flux from the interior into the bottom boundary of lakes as observed by eddy correlation, Limnol. Oceanogr., 53, 19972006, 2008.

Cota, G. F.: Photoadaptation of high Arctic ice algae, Nature, 315, 219-222, 1985.
Crusius, J., Berg, P., Koopmans, D. J., and Erban, L.: Eddy correlation measurements of submarine groundwater discharge, Mar. Chem., 109, 77-85, 2008.

Eicken, H.: From the microscopic, to the macroscopic, to the regional scale: Growth, microstructure and properties of sea ice, in: Sea Ice, An Introduction to its Physics, Chemistry and Biology, edited by: Thomas, D. N. and Dieckmann, G. S., Blackwell Publishing, Oxford, 402 pp., 2003.

Fenchel, T. and Glud, R. N.: Benthic primary production and $\mathrm{O}_{2}-$ $\mathrm{CO}_{2}$ dynamics in a shallow-water sediment: spatial and temporal heterogeneity, Ophelia, 53, 159-171, 2000.

Fofonoff, N. and Millard, R.: Algorithm for computation of fundamental properties of seawater, UNESCO Technical Papers in Marine Science, No. 44, 1983.

Glud, R. N., Rysgaard, S., and Kuhl, M.: A laboratory study on $\mathrm{O}_{2}$ dynamics and photosynthesis in ice algal communities: Quantification by microsensors, $\mathrm{O}_{2}$ exchange rates, ${ }^{14} \mathrm{C}$ incubations and a PAM fluorometer, Aquat. Microb. Ecol., 27, 301-311, 2002.

Glud, R. N., Woelfel, J., Karsten, U., Kuhl, M., and Rysgaard, S.: Benthic microalgal production in the Arctic: Applied methods and status of the current database, Bot. Marin., 52, 559-571, 2009.

Glud, R. N., Berg, P., Hume, A., Batty, P., Blicher, M. E., Lennert, K., and Rysgaard, S.: Benthic oxygen exchange across hardbottom substrates quantified by eddy correlation in a sub-Arctic fjord, Mar. Ecol. Prog. Ser., 417, 1-12, 2010.

Gosselin, M., Legendre, L., Therriault, J.-C., Demers, S., Rochet, M.: Physical control of the horizontal patchiness of sea ice microalgae, Mar. Ecol. Prog. Ser., 29, 289-298, 1986.

Gradinger, R.: Sea-ice algae: Major contributions to primary production and algal biomass in the Chukchi and Beaufort Seas during May/June 2002, Deep-Sea Res. Pt. II, 56, 1201-1212, 2009.

Harvey, A. H.: Properties of Ice and Supercooled Water, in: CRC Handbook of Chemistry and Physics, 92nd Edn., edited by: Lide, D. R., CRC Press, Boca Raton, FL., 2656 pp., 2010.

Hume, A. C., Berg, P., and McGlathery, K. J.: Dissolved oxygen fluxes and ecosystem metabolism in an eelgrass (Zostera marina) meadow measured with the eddy correlation technique, Limnol. Oceanogr., 56, 86-96, 2011.

Kuhl, M., Glud, R. N., Borum, J., Roberts, R., and Rysgaard, S.: Photosynthetic performance of surface-associated algae below sea ice as measured with a pulse amplitude-modulated (PAM) fluorometer on $\mathrm{O}_{2}$ microsensors, Mar. Ecol. Prog. Ser., 223, 114, 2001.

Kundu, P. K. and Cohen, I. M.: Fluid Mechanics, 4th Edn., Academic Press, 2008.

Kuwae, T., Kamio, K., Inoue, T., Miyoshi, E., and Uchiyama,Y.: Oxygen exchange flux between sediment and water in an intertidal sandflat, measured in-situ by the eddy-correlation method, Mar. Ecol. Prog. Ser., 307, 59-68, 2006.

Lorrai, C., McGinnis, D. F., Berg, P., and Brand, A.: Application of oxygen eddy correlation in aquatic systems, J. Atmos Oceanic Technol., 27, 1533-1546, 2010.

Manes, S. S. and Gradinger, R.: Small scale vertical gradients of Arctic ice algal photophysiological properties, Photosynth. Res.: 102, 53-66, 2009.

McGinnis, D. F., Berg, P., Brand, A., Lorrai, C., Edmonds, T., and Wuest, A.: Measurements of eddy correlation oxygen fluxes in shallow freshwaters: Towards routine applications and analysis, 
Geophys. Res. Lett., 35, 1-5, 2008.

McGinnis, D. F., Glud, R. N., Lorke, A., Lennert, K., amd Rysgaard, S.: Turbulence and heat flux under land-fast Arctic Sea ice, The driving forces of ice melt, in prep., 2012.

McMinn, A. and Ashworth, C.: The use of oxygen microelectrodes to determine the net production by an Arctic sea ice algal community, Antarctic Sci., 10, 39-44, 1998.

McMinn, A., Ryan, K. G., Ralph, P. J., and Pankowski, A.: Spring sea ice photosynthesis, primary production and biomass distribution in eastern Antarctica, 2002-2004, Mar. Biol., 151, 985-995, 2007.

McMinn, A., Pankowskii, A., Ashworth, C., Bhagooli, R., Ralph, P., and Ryan, K.: In situ net primary productivity and photosynthesis of Antarctic sea ice algal, phytoplankton and benthic algal communities, Mar. Biol., 157, 1345-1356, 2010.

McPhee, M. G.: Turbulent heat flux in the upper ocean under sea ice, J. Geophys. Res., 97, 5365-5379, 1992.

McPhee, M. G., Morison, J. H., and Nilsen, F.: Revisiting heat and salt exchange at the ice-ocean interface: Ocean flux and modeling considerations, J. Geophys. Res., 113, C06014, doi:10.1029/2007JC004383, 2008.

Mikkelsen, D. M., Rysgaard, S., and Glud, R. N.: Microbial composition and primary production in Arctic se ice: A seasonal study from Kobbefjord (Kangerluarsunnguaq), West Greenland, Mar. Ecol. Prog. Ser., 368, 65-74, 2008.

Mock, T. and Gradinger, R.: Determination of Arctic ice algal production with a new in situ incubation technique, Mar. Ecol. Prog. Ser., 177, 15-26, 1999.

Mock, T., Kruse, M., and Dieckmann, G. S.: A new microcosm to investigate oxygen dynamics at the sea ice-water interface, Aquat. Microb. Ecol., 30, 197-205, 2003.

Platt, T., Gallegos, C. L., and Harrison, W. G.: Photoinhibition of photosynthesis in natural assemblages of marine phytoplankton, J. Mar. Res., 38, 687-701, 1980.
Reimers, C. E., Tuba Ozkan-Haller, H., Berg, P., Devol, A., McCann-Grosvenor, K., and Sanders, R. D.: Benthic oxygen consumption rates during hypoxic conditions on the Oregon continental shelf: Evaluation of the eddy correlation method, J. Geophys. Res., 117, 1-18, 2012.

Rysgaard, S. and Glud, R. N.: Anaerobic $\mathrm{N}_{2}$ production in Arctic sea ice, Limnol. Oceanogr., 49, 86-94, 2004.

Rysgaard, S., Kuhl, M., Glud, R. N., and Hansen, J. W.: Biomass, production and horizontal patchiness of sea ice algae in a highArctic fjord (Young Sound, NE Greenland), Mar. Ecol. Prog. Ser., 223, 15-26, 2001.

Rysgaard, S., Glud, R. N., Sejr, M. K., Blicher, M. E., and Stahl, H. J.: Denitrification activity and oxygen dynamics in Arctic sea ice, Polar Biol., 31, 527-537, 2008.

Shirasawa, K., Ingram, R. G., and Hudier, E. J. J.: Oceanic heat fluxes under thin sea ice in Saroma-ko Lagoon, Hokkaido, Japan, J. Mar. Sys., 11, 9-19, 1997.

Smith, R. E. H., Anning, J., Clement, P., and Cota, G.: Abundance and production of ice algae in Resolute Passage, Canadian Arctic, Mar. Ecol. Prog. Ser., 48, 251-263, 1988.

Søgaard, D. H., Kristensen, M., Rysgaard, S., Glud, R. N., Hansen, P. J., and Hilligsoe, K. M.: Autotrophic and heterotrophic activity in Arctic first-year sea ice: Seasonal study from Malene Bight, SW Greenland, Mar. Ecol. Prog. Ser., 419, 31-45, 2010.

Søgaard, D. H., Rysgaard, S., and Glud, R. N.: Spatial and temporal variation of calcium carbonate crystals, dissolved organic carbon, dissolved inorganic carbon, total alkalinity and nutrients in Subarctic first-year sea ice (SW Greenland), in prep., 2012.

Suzuki, Y., Kudoh, S., and Takahashi, M.: Photosynthetic and respiratory characteristics of an Arctic ice algal community living in low light and low temperature conditions, J. Mar. Syst., 11, 111-121, 1997.

Widell, K., Fer, I., and Haugan, P. M.: Salt release from warming sea ice, Geophys. Res. Lett., 33, L12501, doi:10.1029/2006GL026262, 2006. 